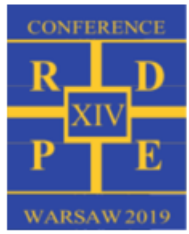

\title{
Modeling of influence of vibration on intensification of heat transfer within the absorber of the vacuum solar collector
}

\author{
Krzysztof Grzywnowicz ${ }^{1, *}$, Lukasz B artela ${ }^{2}$, Leszek Remiorz ${ }^{3}$ and Bartosz Stanek ${ }^{4}$ \\ ${ }^{1}$ Silesian University of Technology, Institute of Power Engineering and Turbomachinery, 44-100 G liwice, ul. K onarskiego 18; \\ krzysztof.grzywnowicz@polsl.pl; Poland \\ ${ }^{2}$ Silesian University of Technology, Institute of Power Engineering and Turbomachinery, 44-100 Gliwice, ul. K onarskiego 18; \\ lukasz.bartela@polsl.pl; Poland \\ ${ }^{3}$ Silesian University of Technology, Institute of Power Engineering and Turbomachinery, 44-100 Gliwice, ul. Konarskiego 18; \\ leszek.remiorz@polsl.pl; Poland \\ ${ }^{4}$ Silesian University of Technology, Institute of Power Engineering and Turbomachinery, 44-100 G liwice, ul. K onarskiego 18; \\ bartosz.stanek@polsl.pl; Poland
}

\begin{abstract}
Due to escalating role of mitigation of climate change in power and energy sector, power units based on renewable energy sources (RES) became vital part of global power and heat market, including distributed heat generation as well. Significant number of such installations belong to individual users, commonly using solar collectors to prepare domestic hot water directly at their sites. However, the vitally variable solar irradiance makes the solar energy difficult in efficient harvesting considering long time period. Thus, maximization of power gain from single solar absorber, when the solar radiation flux is temporarily high, might lead to further rise in overall, year-averaged efficiency of such units. The paper concerns modelling of intensification of heat transfer, taking place within the absorber of a vacuum solar collector, due to insertion of vibrating element inside the thermal oil canal, compared to static turbulization method. Different geometries of vibrating elements and amplitudes of oscillatory motion, as well as heat carriers, are investigated using commercially available CFD software. Results indicate rise in solar power acquired within the absorber using vibrating elements, with essential difference between circulating media, and suggest vital benefits from utilization of static turbulizing devices.
\end{abstract}

\section{Introduction}

Although fossil fuels remain fundamental for worldwide energy sector, their continuous depletion lead to the widespread introduction to the global power and heat sector of power technologies based on renewable energy sources (RES) in last decades [1]. Due to their high seasonal and day-by-day instability of operation, the RES-based technologies were widely introduced to the distributed energy sector [2]. Among all primary energy sources, the solar energy shares an essential part within the distributed RES-based units [1]. Solar irradiance might be obviously utilized both to generate current within the photovoltaic (PV) cells, as well as to produce useful heat within the thermal collectors; nevertheless, hybrid units, producing both forms of the useful energy, are applied as well [1]. A part from global rise of PV modules manufactured and installed, observed recently, the thermal technology continues to play significant role in utilization of solar energy, mainly due to its typical higher efficiency [1]. Nevertheless, due to the short-time, seasonal and year-by-year variability of radiation, followed by essential fluctuations caused by weather conditions and location-based sunrays accessibility, number of technologies, devoted to enhance energy output from PV or solar thermal units, has been investigated. One of these technologies focuses on concentration of direct solar radiation on strictly identified part of the energy receiver, introducing limitation to radiation dissipation and other energy losses [3].

The solar irradiance concentrators, due to their high applicability both within the PV, thermoelectric and thermal units [4], state matter of recent profound investigation. Research, discussed in the literature, focuses on broad variety of topics, beginning with geometry and materials, through modelling of the concentrators' optical properties, up to design and optimization of complex systems.

Strong investigational emphasis is put on optical analysis of geometry of parabolic trough collectors (PTC), primarily due to its potentially low manufacturing costs and easy implementation $[5,6,7]$. Current investigation focuses on application of advanced measuring devices [5] to determine accurate optical properties of reflective surfaces and introduce fundamentals of their optimization [6]. Experimental research on other traditional geometry of the parabolic satellite dish (PSD) has been performed recently as well [8], concerning mainly comparison of such concentration devices with other available geometries. Profound study has been given to the conical solar concentrators [9] as 
well, including design strategy of complete installations. N evertheless, due to no strict limitations of length of the absorbing body, the aplanat geometry concentrators [10] seem to be comparably more beneficial. A part from classical geometry studies, vital focus has been recently given to rapidly developing two-stage solar concentrators [4] and spectrum-splitting units [11,12], which might introduce significant benefits to the solar thermal power devices in the future. Alternatively, optimization of the renowned solutions $[6,7,13]$ might introduce the vital benefits for state-of-the-art technology and bridge the gap between current marketavailability and laboratory-scale research.

Nevertheless, in spite of numerous advantages, utilization of solar concentrators leads to essential challenges, including high risk of photovoltaic cells overheating or local phase transition or degradation of working fluid within the solar thermal collectors [14,15]. Primary drawback connected to appearance of gaseous phase or local degradation of properties of the working fluid, even considering it as present only within a thin film located directly at the irradiated walls, might be vital drop in convective heat transfer between the internal wall of solar thermal collector's absorber and circulating medium. This is followed by danger of potential damage within the device, as well as sudden drop of thermal properties of the heat carrying fluid $[3,14]$. Therefore, intensification of heat transfer within the absorbers of solar collectors is vital especially for installations concentrating solar irradiance.

The literature derives description of several investigations, focused on the discussed issue, concerning utilization of nanoparticles of carbon structures [16], copper [17] or copper oxide [18] to enhance the conduction through the interior of the circulating heat carrier. As the initial results indicate, utilization of thermal oil-based nanofluids within the solar collectors might introduce a breakthrough; nevertheless, the long-term investigation of influence of such fluids on total lifetime of installation has not been reported yet. Therefore, research on geometry of twisted or coil-like turbulizing elements [19] along with strongly aligned ribs [20] and wedge-shaped vertices producing elements [21] remains essential.

However, the investigations has not considered utilization of vibrating elements to enhance the heat transfer due to turbulization of the flow of external circulating medium. Although considerably positive effect of vibrations on heat dissipation has been investigated and discussed [22,23], its applicability within the solar thermal collectors has not be investigated yet.

The main aim of the paper was to perform computational analysis of the effect of utilization of vibrating elements, as the source of turbulences enhancing the convective heat transfer, on operational parameters of the medium-temperature parabolic trough collector (PTC). The research was performed as the introductory investigation, preceding further experimental analysis, performed on currently designed and constructed, dedicated test-stand. In order to compare the proposed method of enhancement of convection, which might introduce certain complexity to the traditional installations, two reference cases of static turbulizing elements, were modelled as well. In order to increase accuracy of the simulation, a 3D model was prepared and numerically analyzed using marketavailable computational fluid dynamics (CFD) software.

\section{Computational Model}

The prepared numerical model considered the geometry of a concentrated solar irradiance receiver in the form of cylindrical absorber, made of structural steel. The assumed geometry of the absorber is presented in Fig. 1.

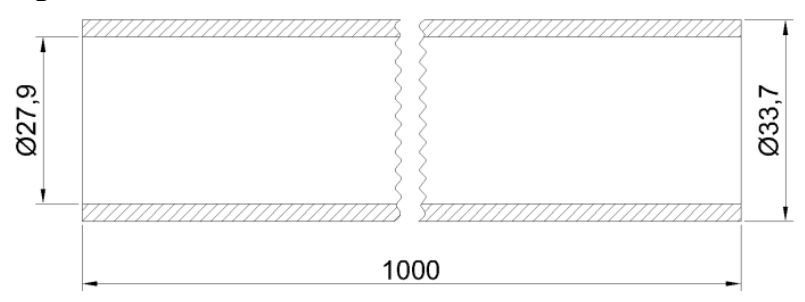

Fig. 1. Scheme of the modelled absorber geometry.

In order to simplify the geometry, the parabolic trough, assumed as the concentrating element of the parabolic trough collector (PTC) unit, was not considered in CFD modelling. Nevertheless, in order to estimate the boundary conditions on the absorber's external surface, computational ray tracing and determination of irradiance was performed using the APEX $^{\mathrm{TM}}$ optical analysis software. The computations, performed in the APEX ${ }^{\mathrm{TM}}$, included preparation of threedimensional geometry of the parabolic concentrator, assumed to be used in a standard PTC installation, selection of the coating, basing on available library of properties of coatings, and final calculations of direct sunlight reflection, including advanced ray tracing using Monte Carlo method and the ray energy averaging. The optical model of the parabolic trough with part of the cylindrical absorber, presenting the ray tracing results, is shown in Fig. 2.

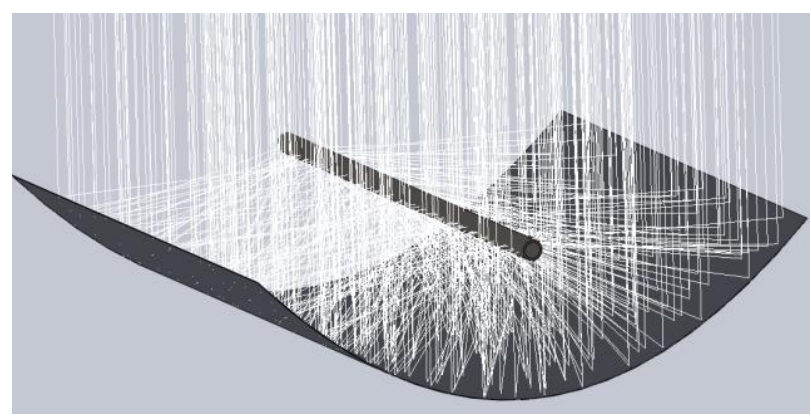

Fig. 2. Scheme of the optical model of the PTC.

However, the optical analysis resulted in identification of essential boundary conditions, required to be inserted within the CFD investigation. These included the average angle, which under the concentrated irradiance is transferred to the absorber's 
surface, and the mean radiative heat flux, enforcing the appearance of thermal phenomena within the absorber.

Further boundary conditions of the model, including primarily inlet and outlet parameters, were identified on the basis of holistic analysis of the general dataset for parabolic trough solar collectors [3]. The properties of the circulating fluid, vitally influencing both heat transfer conditions, scale of a viscous boundary layer and pressure losses, were based on the literature [24]. In order to investigate influence of circulating fluid properties, two different media were assumed - as a reference case, the hydrogenated terphenyl-based thermal oil, and pure water as an additional case. Furthermore, in accordance with data derived by numerical optical analysis of the unit and initial experimental tests of similar installation, two different concentrated radiation angles were identified. This resulted in preparation of two absorber geometries, differing in slicing planes angle, which was used to separate areas radiated by concentrated and direct nonconcentrated light.

The geometrical and environmental boundary conditions, set during the simulation, are concluded in Table 1.

Table 1. The most relevant boundary conditions

\begin{tabular}{|l|c|}
\hline & Value \\
\hline $\begin{array}{l}\text { Angle of concentrated irradiance lighting, } \\
\text { degrees }\end{array}$ & 166.0 \\
\hline $\begin{array}{l}\text { Total area of absorber, irradiated by } \\
\text { concentrated light, mm }\end{array}$ & $48.5 \times 10^{3}$ \\
\hline Emissivity of the absorber walls, - & $3.5 \times 10^{-1}$ \\
\hline $\begin{array}{l}\text { Irradiance transferred to the directly } \\
\text { irradiated surface, W/m }\end{array}$ & 1000.0 \\
\hline $\begin{array}{l}\text { Radiative heat flux on the absorber surface, } \\
\text { W }\end{array}$ & 708.6 \\
\hline $\begin{array}{l}\text { Initial temperature of the absorber' walls, } \\
\text { Celsius degrees }\end{array}$ & 314.6 \\
\hline Mean pressure of the circulating fluid, atm & 1.1 \\
\hline $\begin{array}{l}\text { Initial temperature of the circulating fluid, } \\
\text { Celsius degrees }\end{array}$ & 30.0 \\
\hline $\begin{array}{l}\text { Mass flow rate of circulating fluid at the } \\
\text { absorber's inlet, kg/s }\end{array}$ & $9.9 \times 10^{-3}$ \\
\hline
\end{tabular}

A part from the boundary conditions, set at the external surfaces of the control volume of the numerical model, vital consideration has been given to the model equations. The main issue focused on selection and implementation of highly-reliable, stable and accurate models of turbulences, expected to arise within the boundary layer both by implementing the static turbulizing devices and vibrating elements. Essential challenge, considering such selection, is the partially unknown and variable nature of turbulent vertices, occurring within the fluid domain due to presence of static or vibrating elements. Thus, either two separate models, covering separate cases of turbulence sources might be introduced, or one complete model, covering possibly wide range of turbulence nature might be implemented. Following the last concept, the Reynolds stress model, indicated by Eq. (1), in the SSG variant [25], was assumed. In order to define pressure and velocity distribution at the entrance and outlet of the absorber, the zero gradient model [26], given by Eq. (2) has been applied to these boundaries.

$$
\begin{aligned}
& \frac{\partial}{\partial t}\left(\rho \overline{u_{\imath}^{\prime} u_{\jmath}^{\prime}}\right)+\frac{\partial}{\partial x_{k}}\left(\rho u_{k} \overline{u^{\prime}{ }_{\imath} u_{\jmath}^{\prime}}\right)=-\frac{\partial}{\partial x_{k}}\left[\rho \overline{u_{\imath}{ }_{\imath} u_{\jmath}^{\prime} u^{\prime}{ }_{k}}+\right. \\
& \left.\overline{p^{\prime}\left(\delta_{k j} u_{l}^{\prime}+\delta_{l k} u_{j}^{\prime}\right)}\right]+\frac{\partial}{\partial x_{k}}\left[\mu \frac{\partial}{\partial x_{k}}\left(\overline{u_{\imath}^{\prime} u_{\jmath}^{\prime}}\right)\right]- \\
& \rho\left(\overline{u^{\prime}{ }_{l} u^{\prime}{ }_{k}} \frac{\partial u_{j}}{\partial x_{k}}+\overline{u_{j}^{\prime} u^{\prime}{ }_{k}} \frac{\partial u_{i}}{\partial x_{k}}\right)+\overline{p^{\prime}\left(\frac{\partial u_{l}^{\prime}}{\partial x_{j}}+\frac{\partial u_{J}^{\prime}}{\partial x_{l}}\right)}- \\
& 2 \mu \overline{\frac{\partial u_{l}^{\prime}}{\partial x_{k}} \frac{\partial u_{J}^{\prime}}{\partial x_{k}}}-2 \rho \Omega_{k}\left(\overline{u_{j}^{\prime} u_{m}^{\prime}} \varepsilon_{i k m}+\overline{u_{\imath}^{\prime} u_{m}^{\prime}} \varepsilon_{j k m}\right) \\
& \left\{\begin{array}{c}
-\frac{\partial P}{\partial x}+\frac{d}{d y}\left(\mu \frac{d U}{d y}-\rho \overline{u^{\prime} v^{\prime}}\right)=0 \\
-\frac{\partial P}{\partial y}+\frac{d}{d y}\left(-\rho \overline{u^{\prime} v^{\prime}}\right)=0
\end{array}\right.
\end{aligned}
$$

where: $\mathrm{t}$ - time, $\overline{u_{\imath}^{\prime} u^{\prime}{ }_{j} u^{\prime}{ }_{k}}$ - individual Reynolds stresses, $\rho$-density of the fluid, $x_{k}$ - boundary layer coordinate, $p$ - pressure, $\mu$-dynamic viscosity of fluid, $\varepsilon_{i k m}$ - dissipation term, $v$ - kinematic viscosity of fluid.

Further consideration has been given to the selection of radiation model - since the radiation is the only way of energy propagation outside the external absorber' surface and might vitally contribute to the heat transfer at the absorber-fluid internal interface, high accuracy of modelling was strongly required. Thus, the M onte Carlo and Discrete Transfer models, available within the ANSYS $^{\mathrm{TM}} \mathrm{CFX}^{\mathrm{TM}}$ software, were considered. However, since utilization of the M onte Carlo model, in spite of its accuracy, especially considering complex systems [27], leads to high computational cost, the more time- and energy-efficient model of Discrete Transfer, given by Eq. (3), was assumed [27]. Furthermore, in order to increase the accuracy of results and cover fundamental radiation physics within the domain of circulating heat carrier, the spectral model of gray body was assumed as well.

$$
\frac{d I}{d S}+a I=\frac{a \sigma T^{4}}{\pi}
$$

where: a - fluid absorption coefficient, I - radiation intensity, $\sigma$ - Stefan-Boltzmann constant, T - local temperature.

Finally, the convective heat transfer between the circulating fluid and the absorber was modelled as well. Determination of convective heat transfer coefficient, fundamental for accurate inclusion of thermal effect in total energy balance, was assumed to be performed using the correlation formula. Due to highly unstable conditions within the absorber, as well as development of viscous boundary layer due to sudden enforcement of thermal fluid motion, the correlation for simultaneously thermally and hydrodynamically developing flow, given by literature [28] was selected. Prepared model was also tested under variable meshing parameters and different timesteps to validate by reaching stable outputs. 


\section{Results and Discussion}

The results of the numerical simulations are presented in the form of temperature distributions at the absorber's outlet, indicated on Fig.3 to Fig.6.

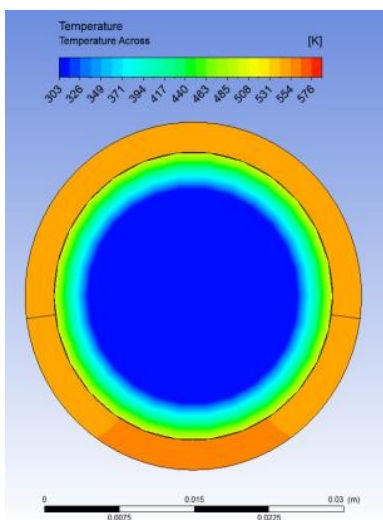

Fig. 3. Temperature

distribution at the absorber's outlet for thermal oil used as a working medium and vibration amplitude of $\delta=0.1 \mathrm{~mm}$

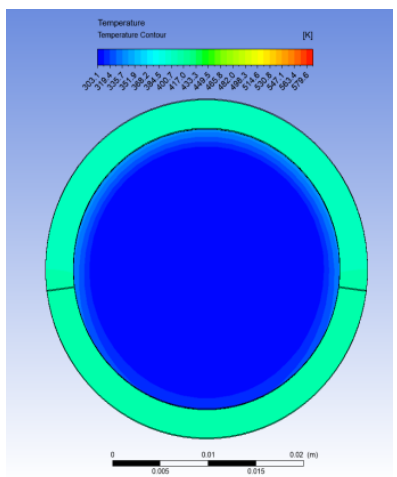

Fig. 5. Temperature

distribution at the absorber's outlet for water used as a working medium and vibration amplitude of $\delta=0.1 \mathrm{~mm}$

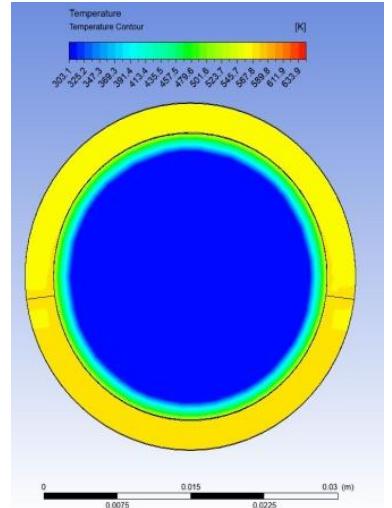

Fig. 4. Temperature distribution at the absorber's outlet for thermal oil used as a working medium and vibration amplitude of $\delta=0.9 \mathrm{~mm}$

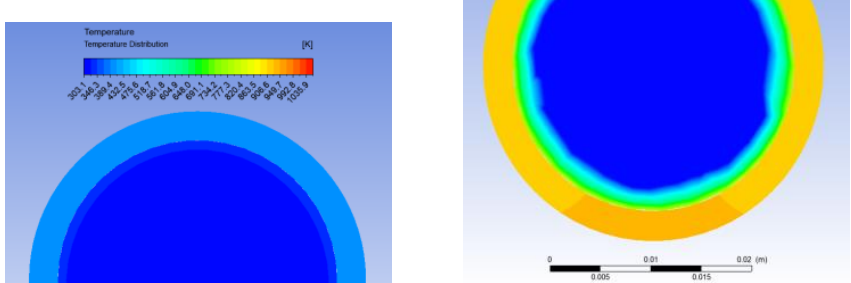

Fig. 9. Temperature

distribution at the absorber's outlet for thermal oil used as a working medium and static turbulizing device with 7 revolutions/meter

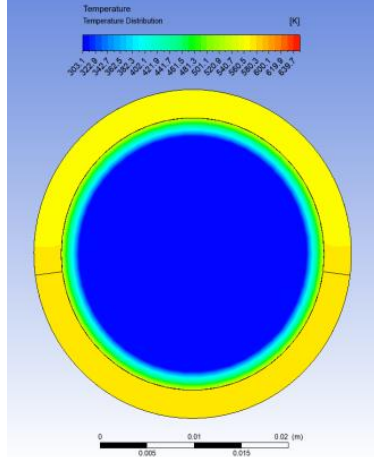

Fig. 8. Temperature distribution at the absorber's outlet for thermal oil used as a working medium and vibration amplitude of $\delta=0.9 \mathrm{~mm}$ and frequency $\mathrm{f}=75 \mathrm{~Hz}$

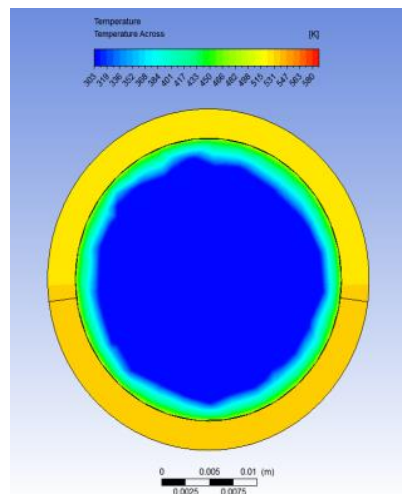

Fig. 10. Temperature

distribution at the absorber's outlet for thermal oil used as a working medium and static turbulizing device with 12 revolutions/meter
Fig. 6. Temperature

distribution at the absorber's outlet for water used as a working medium and vibration amplitude of $\delta=0.9 \mathrm{~mm}$
Results of the analysis, concerning influence of the increase in the frequency of vibrations of the absorber on the operational parameters of the absorber, are indicated in Fig. 7 and Fig. 8. Results of the simulation of the operation of static turbulizing devices, as well as the detailed analysis of the turbulence caused, depicted as distributions of the turbulence kinetic energy, are depicted on Fig. 9 to Fig. 12. Table 2 presents mean values of the circulating medium temperatures at the outlet of the absorber for all simulated cases.

Considering the results acquired for the thermal oil, used as a working medium (Fig. 3 and Fig. 4), no significant difference within temperature distribution, especially concerning the viscous boundary layer within interior if the absorber, is visible. This observation suggests, that the investigated amplitude of vibration does not derive energy required to induce the boundarylayer turbulences, affecting the significant change in temperature distribution around boundary.

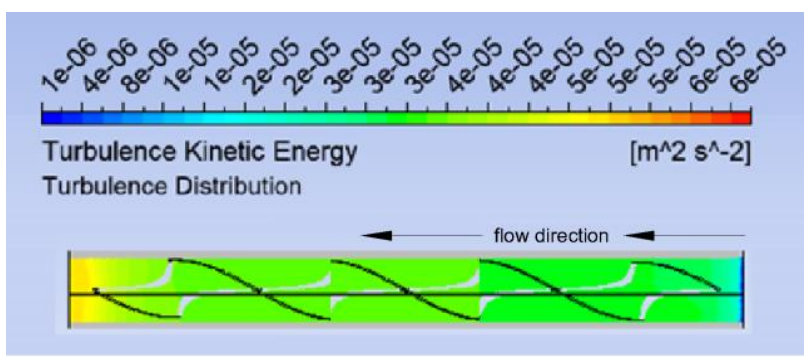

Fig. 11. Turbulence kinetic energy distribution on vertical coaxial plane for static turbulizing device with 7 revs/meter

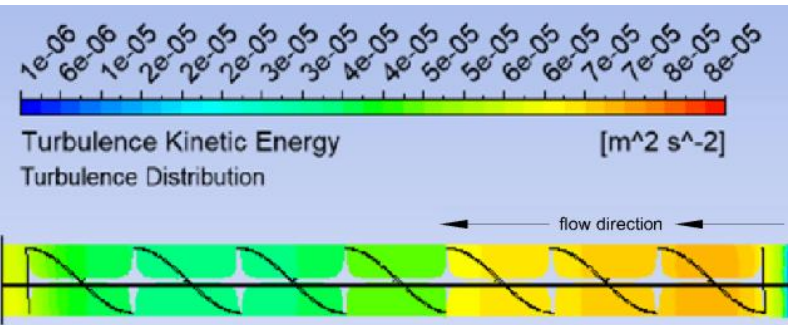

Fig. 12. Turbulence kinetic energy distribution on vertical coaxial plane for static turbulizing device with 12 revs/meter 
Table 2. Mean temperature of the working fluid at the outlet of the absorber - comparison of simulated cases.

\begin{tabular}{|l|c|}
\hline \multicolumn{1}{|c|}{ Case description } & Mean temperature, $\mathbf{K}$ \\
\hline Thermal oil, no turbulization $[29]$ & 305.0 \\
\hline $\begin{array}{l}\text { Thermal oil, vibration of } f=50 \mathrm{~Hz} \\
\text { and } \delta=0.1 \mathrm{~mm}\end{array}$ & 304.5 \\
\hline $\begin{array}{l}\text { Thermal oil, vibration of } f=50 \mathrm{~Hz} \\
\text { and } \delta=0.9 \mathrm{~mm}\end{array}$ & 304.6 \\
\hline Water, no turbulization [29] & 307.9 \\
\hline $\begin{array}{l}\text { Water, vibration of } f=50 \mathrm{~Hz} \text { and } \\
\delta=0.1 \mathrm{~mm}\end{array}$ & 307.9 \\
\hline $\begin{array}{l}\text { Water, vibration of } f=50 \mathrm{~Hz} \text { and } \\
\delta=0.9 \mathrm{~mm}\end{array}$ & 307.8 \\
\hline $\begin{array}{l}\text { Thermal oil, vibration of } f=75 \mathrm{~Hz} \\
\text { and } \delta=0.1 \mathrm{~mm}\end{array}$ & 305.0 \\
\hline $\begin{array}{l}\text { Thermal oil, vibration of } f=75 \mathrm{~Hz} \\
\text { and } \delta=0.9 \mathrm{~mm}\end{array}$ & 305.0 \\
\hline $\begin{array}{l}\text { Thermal oil, static turbulizing } \\
\text { device with } 7 \text { revs } / \mathrm{m}\end{array}$ & 309.9 \\
\hline $\begin{array}{l}\text { Thermal oil, static turbulizing } \\
\text { device with } 12 \text { revs } / \mathrm{m}\end{array}$ & 310.8 \\
\hline
\end{tabular}

The proposed summary of the initial results is supported by data collected for analogical simulation, with water used as a circulating fluid (Fig. 5 and Fig. 6), on which the distortion of the boundary-layer temperature distribution is visible. The difference in temperature of the absorbers between the water and oil fluids is caused by vital difference in transient heat transfer conditions, taking place at the initial phase of the simulation. However, since the heat transfer analysis for water-cooled absorber did not state objective of the research, no detailed investigation has been performed.

A lthough the vibration influenced the boundary layer in the discussed case, energy derived still was not sufficient to vitally turbulize the flow - despite induction of oscillations, the laminar flow was maintained. Therefore, blending the colder and warmer layers of the interior and the boundary-layer of the circulating fluid, leading to vital intensification of heat transfer within the absorber, require higher parameters of the oscillatory motion. This observation is in accordance with the results acquired for simulations performed with the increased frequency of the oscillations (Fig. 7 and Fig. 8). Independently on the amplitude of the vibration, the rise of the frequency of $50 \%$ comparing to the initial case, which results are presented in Fig. 3 and Fig. 4, no significant change within the structure of the boundary layer and the outlet temperature distribution was observed. This is followed by insignificant change in the mean temperature of the working medium between discussed cases, as indicated in Table 2. Vibrations characterized by low acoustic frequencies cannot introduce significant effect on intensification of heat transfer within the solar absorber, shall be stated. This is influenced primarily by high viscosity of the circulating fluid (approximately 120 times greater than the viscosity of water at the ambient temperature [24]), resulting in creation of large viscous boundary layer at the absorber- fluid interface, as well as low range of the frequencies assumed for the simulation [23].

Considering results collected for the static turbulizing devices, analysis of data depicted on Fig. 9 and Fig. 10 proves significant destabilization of laminar flow at the absorber-wall boundary. Considering both cases, essential distortion of the uniform temperature field is indicated/ The distortion directly leads to rise in the mean thermal oil temperature, as data in Table 2 indicates. Nevertheless, regarding results of the turbulence intensity analysis (Fig. 11 and Fig. 12), the element characterized with 12 revolutions per meter introduces slightly higher turbulence kinetic energy, compared to the other investigated element. Furthermore, for this geometry, the highest values of the turbulence kinetic energy are observed at the inlet to the absorber and close to the inlet, whereas for the second of discussed geometries, the highest energy was observed for the absorber's outlet plane. Nevertheless, for both cases, significant flow turbulization at the absorber's outlet is visible.

\section{Conclusions}

Results of the performed simulations indicate, that utilization of vibrations of low acoustic frequencies in enhancement of heat transfer within the absorber of vacuum solar collector is strongly limited. The main reason is high viscosity of the terphenyl-based thermal oil, used as the working fluid for high temperature installations, resulting in large thickness of the viscous boundary layer. The simulated vibrations, characterized by frequency not exceeding $f=75 \mathrm{~Hz}$ and amplitude below $\delta=1 \mathrm{~mm}$ do not introduce sufficient kinetic energy to create the boundary-layer vertices, resulting in significant turbulization of the fluid. Nevertheless, further investigation on effect of induction of vibrations of frequency close to the resonant frequency of the system, inspired by the promising results of the analysis discussed in [22], states subject of the future research. Furthermore, due to the introductory nature of the presented computational research, discussed results are aimed to be verified during future experimental investigation.

Data collected for the static turbulizing devices proves possibility of its successful application in absorbers of the solar collectors. B oth the temperature distribution at the absorber's outlet, as well as mean temperature of the circulating fluid, prove positive effect of introduction of both investigated geometries of the turbulizing elements. However, detailed analysis of the turbulence kinetic energy suggests, that increase in the number of revolutions per unitary length leads to rise in the turbulence kinetic energy of the created fluid vertices. Furthermore, for the twelve-revolutions geometry, the majority of turbulent vertices were produced at the region of higher average heat flux, comparing to the case of seven-revolution geometry. The optimization of the constructional features of the turbulizing elements states matter of further investigation. 


\section{Acknowledgments}

The scientific work is funded by the National Science Centre within the framework of the research project $\mathrm{No}$. 2018/29/B/ST 8/02406.

\section{References}

[1] E. K lugmann, E. Klugmann-Radziemska: Ogniwa i moduły fotowoltaiczne oraz inne niekonwencjonalne źródła energii, Ekonomia i Środowisko, Białystok (2005)

[2] G. Lobaccaro, S. Croce, C. Lindkvist, M.C. M unari Probst, A. Scognamiglio, J. Dahlberg, M. Lundgren, M. Wall: A cross-country perspective on solar energy in urban planning: Lessons learned from international case studies, Renewable and Sustainable Energy Reviews, V ol. 108, pp. 209-237 (2019)

[3] W. Gogół, O. Skonieczny, L. Zakrzewski: Niektóre zagadnienia wymiany ciepła $\mathrm{w}$ kolektorach energii promieniowania słonecznego, Politechnika Warszawska, W arszawa 1979

[4] N. Bushra, T. Hartmann: A review of state-of-the-art reflective two-stage solar concentrators: Technology categorization and research trends, Renewable and Sustainable Energy Reviews, V ol. 114, 109307 (2019)

[5] M.E. Y drissi, H. Ghennioui, E.G. Bennouna, A. Farid: Geometric, optical and thermal analysis for solar parabolic trough concentrator efficiency improvement using the Photogrammetry technique under semi-arid climate, Energy Procedia, vol. 157, p. 1050-1060 (2019)

[6] L. Evangelisti, R. De Lieto V ollaro, F. A sdrubali: Latest advances on solar thermal collectors: A comprehensive review, Renewable and Sustainable Energy Reviews, Vol. 114, 109318 (2019)

[7] N. B. Desai, S. B. Kedare, S. Bandyopadhyay: Optimization of design radiation for concentrating solar thermal power plants without storage, Solar Energy, Vol. 107, pp. 98-112 (2014)

[8] J. Ruelas, D. Sauceda, J. Vargas, R. García: Thermal and concentration performance for a wide range of available offset dish solar concentrators, Applied Thermal Engineering, $\mathrm{V}$ ol. 144, pp. 13-20 (2018)

[9] G. H. Lee: Construction of conical solar concentrator with performance evaluation, Energy Procedia, Vol. 153, pp. 137-142 (2018)

[10] E.T.A. Gomes, N. Fraidenraich, O.C. Vilela, C.A.A. Oliveira, J. M. Gordon: A planats and analytic modeling of their optical properties for linear solar concentrators with tubular receivers, Solar Energy, Vol. 191, pp. 697-706 (2019)

[11] C. Michel, P. Blain, L. Clermont, F. Languy, C. Lenaerts, K. Fleury-Frenette, M. Décultot, S. Habraken, D. V andormael, R. Cloots, G. K. V.V. Thalluri, C. Henrist, P. Colson, J. Loicq: Waveguide solar concentrator design with spectrally separated light, Solar Energy, V ol. 157, pp. 10051016 (2017)

[12] G. Wang, Y. Y ao, Z. Chen, P. Hu: Thermodynamic and optical analyses of a hybrid solar CPV/T system with high solar concentrating uniformity based on spectral beam splitting technology, Energy, V ol. 166, pp. 256-266 (2019) [13] J. Chen, L. Y ang, Z. Zhang, J. Wei, J. Y ang: Optimization of a uniform solar concentrator with absorbers of different shapes, Solar Energy, V ol. 158, pp. 396-406 (2017)
[14] P. Selvakumar, P. Somasundaram, P. Thangavel: Performance study on evacuated tube solar collector using Therminol D-12 as heat transfer fluid coupled with parabolic trough, Energy Conversion and Management, Vol. 85, pp. 505-510 (2014)

[15] J. Q in, E. Hu, G. J. N athan, L. Chen: Concentrating or non-concentrating solar collectors for solar Aided Power Generation?, Energy Conversion and Management, Vol. 152 , pp. 281-290 (2017)

[16] M. Sabiha: An experimental study on Evacuated tube solar collector using nanofluids, International Conference on Advances in Science, Engineering, Technology and Natural Resources (ICASETNR-15) Sabah, Malaysia, Vol. 2, pp. $42-49$

[17] M .A. Sharafeldin, G. Gróf, E. A bu-Nada, O. M ahian: Evacuated tube solar collector performance using copper nanofluid: Energy and environmental analysis, Applied Thermal Engineering, Vol. 162, 114205 (2019)

[18] H.Fathabadi: Novel solar collector: Evaluating the impact of nanoparticles added to the collector's working fluid, heat transfer fluid temperature and flow rate, Renewable Energy, DOI: https://doi.org/10.1016/j.renene.2019.10.008 (2019)

[19] A. García, R. Herrero-Martin, J.P. Solano, J. PérezGarcía: The role of insert devices on enhancing heat transfer in a flat-plate solar water collector, Applied Thermal Engineering, V ol. 132, pp. 479-489 (2018)

[20] D. J in, S. Quan, J. Zuo, S. Xu: Numerical investigation of heat transfer enhancement in a solar air heater roughened by multiple V -shaped ribs, Renewable Energy, Vol. 134, pp. $78-88$ (2019)

[21] F. A.S. da Silva, D. J. Dezan, A. V. Pantaleão, L. 0. Salviano: Longitudinal vortex generator applied to heat transfer enhancement of a flat plate solar water heater, Applied Thermal Engineering, V ol. 158, 113790 (2019)

[22] W. Liu, Z. Y ang, B. Zhang, P. Lv: Experimental study on the effects of mechanical vibration on the heat transfer characteristics of tubular laminar flow, International Journal of Heat and Mass Transfer, V ol. 115, Part A, pp. 169-179 (2017)

[23] M. Setareh, M. Saffar-A vval, A . A bdullah:

Experimental and numerical study on heat transfer enhancement using ultrasonic vibration in a double-pipe heat exchanger, Applied Thermal Engineering, Vol. 159, 113867 (2019)

[24] Therminol $₫ 66$ High Performance Highly Stable Heat Transfer Fluid, Solutia Europe S.A./N.V., Louvain-laNeuve (2016)

[25] C.G. Speziale, S. Sarkar, T.B. Gatski: Modeling the Pressure-Strain Correlation of Turbulence: an Invariant Dynamical Systems A pproach, Journal of Fluid Mechanics, Vol. 227, pp. 245-272 (1991)

[26] Bredberg J.: On the Wall Boundary Condition for Turbulence Models, Chalmers University of Technology, Göteborg (2000)

[27] ANSYS CFX-Solver Theory Guide. Release 15.0, A NSY S Inc., Canonsburg (2013)

[28] G.F. Nellis., S.A. Klein: Heat Transfer, Cambridge University Press, N ew Y ork (2009)

[29] Bartela Ł., Remiorz L., Stanek B., Grzywnowicz K.: Kierunki intensyfikacji przepływu ciepła $\mathrm{w}$ absorberze parabolicznego koncentratora promieniowania słonecznego, Konferencja Zarzadzanie Energia i Teleinformatyka, Rynek Gazu, Rynek Ciepła, Nałęczów 17-19.06.2019 